\title{
Thermal changes in young and mature bone nanostructure probed with Ca 2p excitations
}

\author{
A S Konashuk ${ }^{1}$, D O Samoilenkoํㅜ, A Y Klyushin ${ }^{1,2,3}$, G I Svirskiy ${ }^{1}$, S S Sakhonenkov ${ }^{1}$, \\ X O Brykalova ${ }^{1}$, M A Kuz'mina ${ }^{4}$, E O Filatova ${ }^{1}$, A S Vinogradov ${ }^{1}$ and A A Pavlychev ${ }^{1}$
}

${ }^{1}$ Solid State Electronics Department, St-Petersburg State University, St. Petersburg, 198504, Russian Federation

${ }^{2}$ Research Group Catalysis for Energy, Helmholtz Zentrum Berlin, 14109 Berlin, Germany

${ }^{3}$ Fritz-Haber-Institut der Max-Planck-Gesellschaft, Faradayweg 4-6, 14195, Berlin, Germany

${ }^{4}$ Institute of Earth Sciences, Department of Crystallography, St-Petersburg State University, St. Petersburg, 199034, Russian Federation

E-mail: xenia.olegovna@gmail.com

\begin{abstract}
Thermal dependence of mineralized bone structure is examined both experimentally by measuring the near edge X-ray absorption fine structure (NEXAFS) and theoretically by applying the 3DSL model to clarify relationship between the local electronic and atomic structure and hierarchical organization of skeleton. The high energy resolution NEXAFS spectra are acquired near the Ca $2 p$ edges in native bone heated from RT up to $450^{\circ} \mathrm{C}$ and hydroxyapatite $\left(\mathrm{Ca}_{10}\left(\mathrm{PO}_{4}\right)_{6}(\mathrm{OH})_{2}, \mathrm{OH}-\mathrm{Ap}\right)$ to understand the interplay of short-, long- and super-range order parameters of bone matter. Our focus is on the thermal changes of spectral distribution of oscillator strength for $\mathrm{Ca} 2 \mathrm{p}_{1 / 2,3 / 2} \rightarrow 3 \mathrm{~d}$ transition in bone and $\mathrm{OH}$ Ap. The investigations have confirmed the assignment of the OH-Ap-to-bone spectral changes to the predicted hierarchy effect on electronic and atomic structure of mineralized bone. At RT the OH-Apto-bone red shift $\delta E_{3 \mathrm{~d}}$ of the transition energy is found equal $\approx 0.2 \mathrm{eV}$ and $\approx 0.1 \mathrm{eV}$ for mature and young bone respectively. We stated that the shift behaves irregular and its magnitude varies from 0.1 $\mathrm{eV}$ up to $0.3 \mathrm{eV}$ when the heating temperature grows. Two mechanisms associated with the thermalinduced dehydration of the inter-nanocrystallite spaces and with the subsequent atomic restructuring of the nanocrystallite interface in mineralized phase are revealed. We have detected that the OH-Apto-bone red shifts of the $\mathrm{Ca} 2 \mathrm{p} \rightarrow 3 \mathrm{~d}$ transition in young bone are smaller than those of in mature bone. The origin of the age differences is discussed.
\end{abstract}




\section{Introduction}

Hierarchical structuring provides fascinating mechanical properties and high material functionality of bone tissue [1 - 9]. Studying it one can achieve deeper understanding of the hierarchical and self-assembled materials. To date, many efforts have been invested to investigate the role of chemical composition in mechanical and physical properties of bone [10 - 12]. These properties are also tightly related with the skeletal hierarchical organization. Regrettably the hierarchy effect on bone tissue in nanoscale remains without sufficient attention. The hard hydroxyapatite $\left(\mathrm{OH}-\mathrm{Ap}, \mathrm{Ca}_{10}\left(\mathrm{PO}_{4}\right)_{6}(\mathrm{OH})_{2}\right)$ strata in combination with the flexible collagen fibrils make bone more elastic and firm [3-6] than the initial mineral and the collagen molecule. Water is the third basic component $[1,4,6]$, the role of which in physical, chemical and mechanical properties of bone tissue is not completely understood [1, 5, $13-15]$.

Medical treatment and rehabilitation of patients with skeletal pathology is of great socio-economic importance. In particular, osteoarthritis is the fourth most common cause of hospitalization [16]. Material science, biological and medical investigations trace the complicated hierarchy of the skeleton designs from macro- to nanolevel $[1-9,17,18]$. Nanolevel research encounters especially great difficulty because local electronic and atomic structure of bone is not sufficiently studied. This knowledge gap prevents solutions of many fundamental and applied problems, such as bio-design of advanced materials $[3-9,16,19,20]$, controlled ion exchange and paleontological research [21, 22]. Nanolevel studies open a perspective way for medical imaging and nanodiagnostics of bone tissue in normal and pathological conditions.

Recently, theoretical and X-ray spectroscopic investigations are carried out to understand relationship between hierarchical organization of native bone and its local electronic and atomic structure [18]. According to the 3D superlattice (3DSL) model [18] this structure is a subject of complicated interplay of the short-, long- and super-range order parameters of bone material. In particular, the interplay results in the $\mathrm{OH}$-Ap-tobone red shift of the density of electronic states and the core shell to valence shell transitions. The predicted OH-Ap-to-bone spectral changes are proportional to the ratio of the hydrated layer thickness to the linear size of the nanocrystallites of $\mathrm{OH}-\mathrm{Ap}(\mathrm{NOH}-\mathrm{Ap})$ and specify the hierarchy effect on electronic and atomic structure of bone.

Comparison of the experimental near-edge X-ray absorption structure (NEXAFS) spectra of native bone at the $\mathrm{Ca} 2 \mathrm{p}, \mathrm{P} 2 \mathrm{p}$ and $\mathrm{O} 1 \mathrm{~s}$ thresholds with the known spectra of $\mathrm{OH}-\mathrm{Ap}$ has confirmed the prediction. The red shifts of $2 p \rightarrow 3 d$ absorption transitions extracted from the experimental $\mathrm{Ca} \mathrm{L}_{2,3}$ NEXAFS analysis are found varying from $1 \mathrm{eV}$ up to $0.2 \mathrm{eV}[18,23]$. In general these values agree with the model shift $\approx 0.4$ $\mathrm{eV}$ computed in assumption that empty spaces separate the equal NOH-Ap in their coplanar assembly. Note that this estimate gives the maximal value of the red shift [18]. To understand why the larger shifts have been detected the authors of [24] have pointed out that the extracted shifts are obtained from the NEXAFS spectra of bone samples by using different techniques to prepare them and different methods to calibrate the absolute energy of X-ray transitions.

In the present work to avoid these uncertainties our main goal is to measure more accurately the $\mathrm{Ca}$ $2 p_{1 / 2,3 / 2}$ NEXAFS spectra of bone and OH-Ap under the same experimental conditions. Besides, we focus 
on thermal-induced changes in bone tissue to study in more detail the hierarchy effect on electronic and atomic structure of mineralized bone and to check the applicability of the 3DSL model for its description. To probe the thermal properties of native bone the high resolution Ca $2 \mathrm{p}_{1 / 2,3 / 2}$ NEXAFS spectra of bone samples heated from RT up to $450^{\circ} \mathrm{C}$ are measured and examined. Since the thermodynamic equilibrium in them is not realized as the collagen and water networks are subjects of substantial structural changes the heating temperature $\mathrm{T}$ and heating time $\tau$ are used to specify the thermal loads. In the work the time period $\tau$ is fixed whereas the temperature varies. Thus, the $\mathrm{T}$ dependence of the $\mathrm{Ca} 2 \mathrm{p}_{1 / 2,3 / 2}$ NEXAFS is used to probe the thermal properties of native bone.

Heating up to $200^{\circ} \mathrm{C}$ leads to removing of the inter-crystallite water from mineralized phase $[25,26]$. The microthermal analysis and atomic force microscopy of collagen matrix [27] evidences that $65^{\circ} \mathrm{C}, 130^{\circ} \mathrm{C}-$ $180^{\circ} \mathrm{C}, 260^{\circ} \mathrm{C}, 340^{\circ} \mathrm{C}$ and $420^{\circ} \mathrm{C}$ are the transition temperatures for denaturation of native hydrated collagen, evaporation of bound water and denaturation of calcified collagen, conformation changes of the collagen molecules from triple helix structure to random coil, as well as the first and second stages of collagen matrix degradation, respectively. Taking into account the essential structural changes in the collagen fiber and water networks and that thermal loads play a crucial role in hierarchical nanostructures [28] a complicated Tdependence of Ca $2 p$ NEXAFS spectra of mineralized bone is expected. The 3DSL model also predicts irregular thermal changes in electronic and atomic structure of mineralized bone tightly related with the super periodicity of the coplanar assemblies of nanocrystallites.

The experimental details of our spectroscopic studies are described in the section 2. The Tdependences of the $\mathrm{Ca} 2 \mathrm{p}$ NEXAFS spectra and the OH-Ap-to-bone red shifts of the "white" lines are measured for young and mature bone tissue and presented in section 3. To rationalize the observed thermalinduced and age-related changes in mineralized bone the 3DSL model is applied. The dehydration and restructuring mechanisms resulting in the spectral shift and line shape distortion of the $\mathrm{Ca} 2 \mathrm{p}$ excitations in bone matter are discussed in section 4 .

\section{Experimental}

All absorption measurements were carried out using monochromatic synchrotron radiation at the RGBL beamline of the BESSY II synchrotron light source of Helmholtz-Zentrum Berlin. Powdered bone and synthetic apatite samples were used as objects. The bone samples are prepared from cortical middle third of the femur, tibia and humerus white mongrel mature male rats weighting $250-280 \mathrm{~g}$ and young (prenatal) rats weighting $40-60$ g. Cortex has been (i) thoroughly cleaned of soft tissue, (ii) washed in saline, (iii) dried with blotting paper, and (iv) grinded to fine powder with particles of size $\sim 1 \mu \mathrm{m}$. 
The hydroxyapatite of almost stoichiometric composition (a = 9.416 (2) $\AA$, c $=6.880$ (1) $\AA$ ) was synthesized by reverse precipitation method in an ammonium-containing solution. An aqueous solution containing ammonium hydrogen phosphate $\left(\left(\mathrm{NH}_{4}\right)_{2} \mathrm{HPO}_{4}\right)(100 \mathrm{ml} 0.1 \mathrm{~mol} / 1(10 \mathrm{mmol}$ of phosphate ions $))$ was dropped by drop into a stirred solution of calcium nitrate $\left(\mathrm{Ca}\left(\mathrm{NO}_{3}\right)_{2}\right)(200 \mathrm{ml} 0.1 \mathrm{~mol} / \mathrm{l}(20 \mathrm{mmol}$ of calcium ions) heated to $85^{\circ} \mathrm{C}-90^{\circ} \mathrm{C}$. Stirring was carried out continuously for 30 minutes. The required $\mathrm{pH}$ value $=8$ - 11 was maintained by adding concentrated ammonium hydroxide $\left(\mathrm{NH}_{4} \mathrm{OH}\right)$ solution to the ammonium hydrogen phosphate $\left(\left(\mathrm{NH}_{4}\right)_{2} \mathrm{HPO}_{4}\right)$ solution. The resulting solution with a fine-crystalline white precipitate was kept at $\mathrm{T}=90^{\circ} \mathrm{C}-100^{\circ} \mathrm{C}$ for 2 hours. The precipitate was washed by distilled water several times, dried at $100^{\circ} \mathrm{C}-110^{\circ} \mathrm{C}$ for 24 hours, and then grinded in a mortar until the sample was homogenized. The ratio of the calcium cations to the phosphate ions in the solution was at least $2 / 1$ throughout the entire synthesis process to ensure the crystallization of apatite with the $\mathrm{Ca} / \mathrm{P}$ ratio $\sim 1.67$. X-ray diffraction measurements were used to control the atomic structure of synthetic samples. This synthesis method is described in more detail in [A. Nikolaev , M. Kuz'mina, O. Frank-Kamenetskaya, M. Zorina, J. Mol. Structure, 1089 (2015), 73-80].

The samples for X-ray absorption measurements were prepared ex situ in air: the bone and gold powders were mixed and pressed to prepare the pellets. Gold powder was added to reduce the charging of samples during their irradiation with a very intense synchrotron radiation beam. In addition, the samples of the bone tissue and a reference compound (synthesized OH-Ap nanopowder) were prepared by rubbing the bone powders into a scratched surface of a clean substrate (metallic gold sheet $5 \times 5 \mathrm{~mm}^{2}$ in size). The samples were fixed on the holder and introduced into the preparation chamber, where they can be heated in the furnace for 30 minutes at various fixed temperatures $\mathrm{T}$ in the range from $\mathrm{RT}$ to $450^{\circ} \mathrm{C}$. The sample holder temperature was measured using a S-type thermocouple. After the heating the samples were transferred into the measuring chamber.

The samples were placed at the angle of $\sim 45^{\circ}$ with respect to the incident beam of the monochromatic radiation and the size of the focal spot on the sample was around $1 \times 1 \mathrm{~mm}^{2}$. The NEXAFS spectra were measured by recording the total electron yield (TEY) as a function of incident photon energy $h v$. The TEY proportional to the absorption cross section $[29,30]$ was acquired by measuring the drain current from the sample and characterized by probing depths of $>10 \mathrm{~nm}$. X-ray absorption investigations were performed in the measuring chamber under ultrahigh vacuum conditions with a residual gas pressure of $\sim 10^{-9}$ mbar. No remarkable charging or decomposition effects for all the samples due to their irradiation with the intense beam of soft X-rays were detected.

The NEXAFS spectra were recorded with a photon-energy resolution of $78 \mathrm{meV}$ for the $\mathrm{Ca} 2 \mathrm{p}$ edge $\left(h v \sim 350 \mathrm{eV}\right.$ ). The photon energy $h v$ over this range was calibrated by measuring $\mathrm{Au} 4 \mathrm{f}_{7 / 2}$ photoelectron peak using photons of the $1^{\text {st }}$ and $2^{\text {nd }}$ orders of diffraction with energies of $355 \mathrm{eV}$ and $710 \mathrm{eV}$, respectively. The energy positions of the $\mathrm{Ca} 2 \mathrm{p}$ absorption structures of the bone samples were determined with an accuracy of about $0.1 \mathrm{eV}$. 


\section{Thermal dependence}

The $\mathrm{Ca} 2 \mathrm{p}$ NEXAFS spectra of the mature and young bone measured at the different heating temperature $\mathrm{T}$ are plotted in figures 1 and 2. Close similarity of the X-ray absorption spectra of bone and OH-Ap is evident. In all spectra the intense resonances $\mathrm{A}$ and $\mathrm{B}$ and the weak structures located on their low-energy sides specify photoabsorption in the spectral interval $346<h v<354 \mathrm{eV}$. The NEXAFS spectra demonstrate a typical spectral distribution of oscillator strength for X-ray transition near the Ca $2 \mathrm{p}_{1 / 2,3 / 2}$ edges in various calcium compounds such as $\mathrm{Ca}_{3}\left(\mathrm{PO}_{4}\right)_{2}, \mathrm{CaCO}_{3}[23,31-35]$. The spectral distribution is dominated by multiplet splitting of the $\mathrm{Ca}^{2+} 2 \mathrm{p}^{5} 3 \mathrm{~d}^{1}$ electronic configuration of the $2 \mathrm{p} \rightarrow 3 \mathrm{~d}$ transition final state in the crystal field. The theoretical investigations $[31,32]$ have assigned the absorption lines $\mathrm{A}$ and $\mathrm{B}$ with the splitting $\mathrm{Ca}^{2+}$ $2 \mathrm{p}^{5} 3 \mathrm{~d}^{1}\left(a_{2}\right)$ and $2 \mathrm{p}^{5} 3 \mathrm{~d}^{1}\left(b_{2}\right)$ components. Their intensities and energy positions depend strongly on the surrounding potential and its point group symmetry. Since they are subjects of changes in bone tissue the labels $a_{2}$ and $b_{2}$ are not regarded here as the corresponding irreducible representations.

By examining the experimental spectra in figures 1 and 2 the distinct deviations of the Ca $2 p$ excitations of bone in comparison with OH-Ap can be revealed. First of all we observe the downward energy shift of the absorption lines A and B relative to their reference positions in the $\mathrm{Ca} 2 \mathrm{p}$ absorption spectra of $\mathrm{OH}-$ Ap. In the figures the vertical solid lines trace the measured positions $349.3 \mathrm{eV}$ and $352.6 \mathrm{eV}$ of the $\mathrm{Ca} 2 \mathrm{p}$ excitations in OH-Ap. The OH-Ap-to-bone red shifts $\delta E_{A(B)}$ of the A and B lines are defined as

$$
\delta E_{A(B)} \equiv E_{O H-A p}^{(A(B))}-E_{\text {bone }}^{(A(B))}
$$

where $E_{O H-A p}^{(A(B))}$ and $E_{b o n e}^{(A(B))}$ are the energy positions of the lines A or B in OH-Ap and native bone respectively. Both the sign and the mean value of the shift $\delta E_{A(B)}$ agree reasonably with our expectations based on the 3DSL model and support the hierarchy effect on the core-to-valence transition energies in mineralized bone predicted and discussed in [18, 24].

By comparing the $\mathrm{Ca} 2 \mathrm{p}$ NEXAFS spectra we also see the distinct thermal-induced and age-related deviations in them. The measured OH-Ap-to-mature-bone $\delta E_{A}^{m}$ and $\delta E_{B}^{m}$ and OH-Ap-to-young-bone $\delta E_{A}^{y}$ and $\delta E_{B}^{y}$ red shifts of the $\mathrm{Ca} 2 \mathrm{p}$ excitations as a function of $\mathrm{T}$ are collected in tables 1 and 2 . The shifts $\delta E_{A}^{m}$ and $\delta E_{B}^{m}$ vary from $0.3 \mathrm{eV}$ up to $0.1 \mathrm{eV}$; the full-width-at-half-maximum (FWHM) demonstrates narrowing up to $-0.1 \mathrm{eV}$ and broadening up to $+0.4 \mathrm{eV}$. Considering the spectra of young bone we see that the thermalinduced changes of both the red shifts and FWHM do not exceed $0.2 \mathrm{eV}$. 


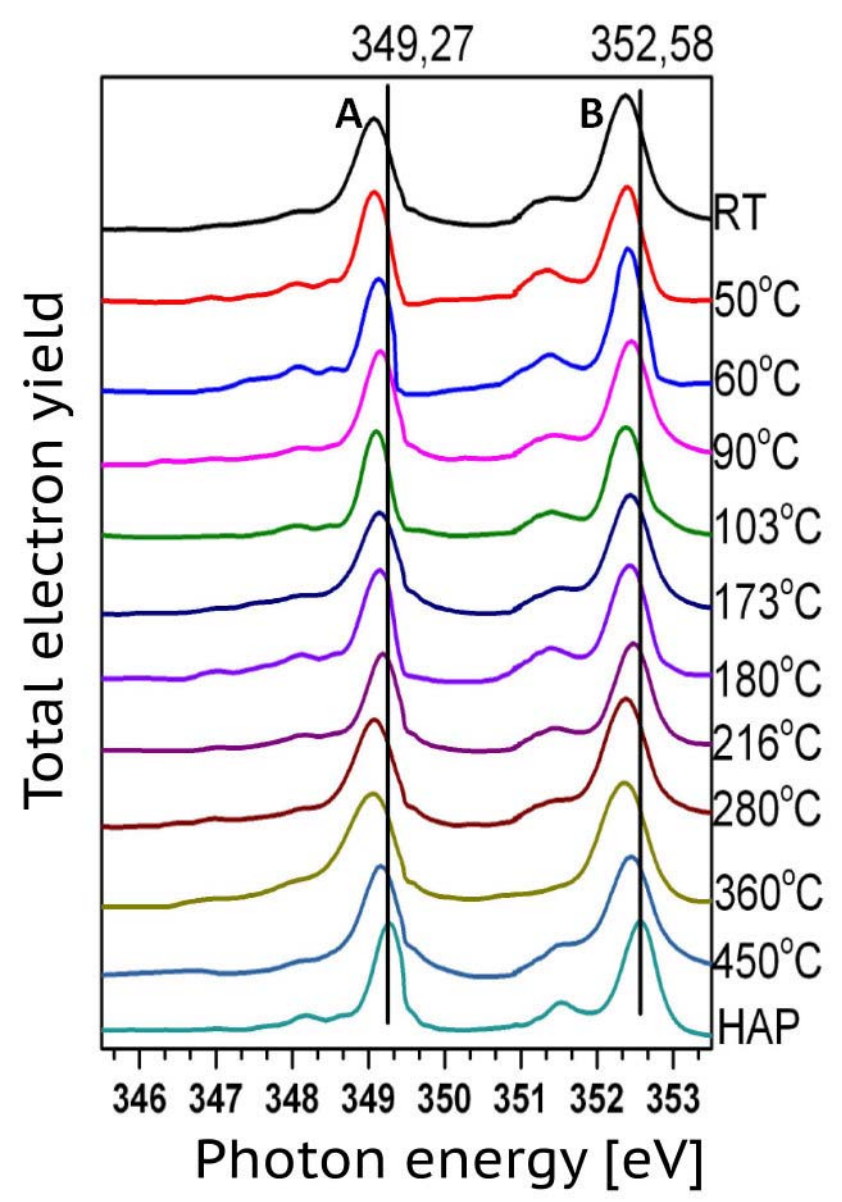

Figure 1. Spectral dependence of the TEY near the Ca 2p edges in native mature bone at RT and heated 30 minutes at the temperature $\mathrm{T}$ marked at the right side. The lowest curve is the reference $\mathrm{Ca} 2 \mathrm{p}$ NEXAFS spectrum of OH-Ap. To visualize the OH-Ap-to-bone red shifts the energy positions of the "white" lines A and B in OH-Ap are shown by the vertical lines.

The OH-Ap-to-bone red shifts for young $(y)$ and mature $(m)$ bone averaged over the thermal interval are found $\left\langle\delta E_{A}^{m}\right\rangle \approx 0.18 \mathrm{eV},\left\langle\delta E_{B}^{m}\right\rangle \approx 0.2 \mathrm{eV},\left\langle\delta E_{A}^{y}\right\rangle \approx\left\langle\delta E_{B}^{y}\right\rangle \approx 0.14 \mathrm{eV}$. So, the shifts of the Ca $2 \mathrm{p} \rightarrow 3 \mathrm{~d}$ transitions in young bone are smaller than those of in mature bone. Note, that the detected shifts $0<$ $\delta E_{A(B)} \leq 0.3 \mathrm{eV}$ are in good agreement with the 3DSL model and with the experimental results presented in $[18,24]$.

Analyzing the thermal dependence of the core-to-valence transitions in mature bone we see that the shift $\delta E_{A}^{m}$ comes through maximums $\approx 0.3 \mathrm{eV}$ at $280^{\circ} \mathrm{C}-360^{\circ} \mathrm{C}$ and the shift $\delta E_{B}^{m}$ reaches the maximums $\approx 0.3 \mathrm{eV}$ at lower $\mathrm{T} \approx 103^{\circ} \mathrm{C}$ and in the interval $280^{\circ} \mathrm{C}-360^{\circ} \mathrm{C}$ too. The both shifts come through the minimum $\approx 0.1 \mathrm{eV}$ at $\mathrm{T} \approx 90^{\circ} \mathrm{C}, 216^{\circ} \mathrm{C}$ and $450^{\circ} \mathrm{C}$. The $\mathrm{OH}$-Ap-to-mature-bone changes in the FWHM demonstrate also the distinct T-dependence. These "white" lines become narrower when T increases from RT up to $60^{\circ} \mathrm{C}$ and broader at higher temperatures. The maximal broadening $\delta W_{A}^{m} \approx \delta W_{B}^{m} \approx 0.4 \mathrm{eV}$ is observed at $360^{\circ} \mathrm{C}$ and $450^{\circ} \mathrm{C}$. 


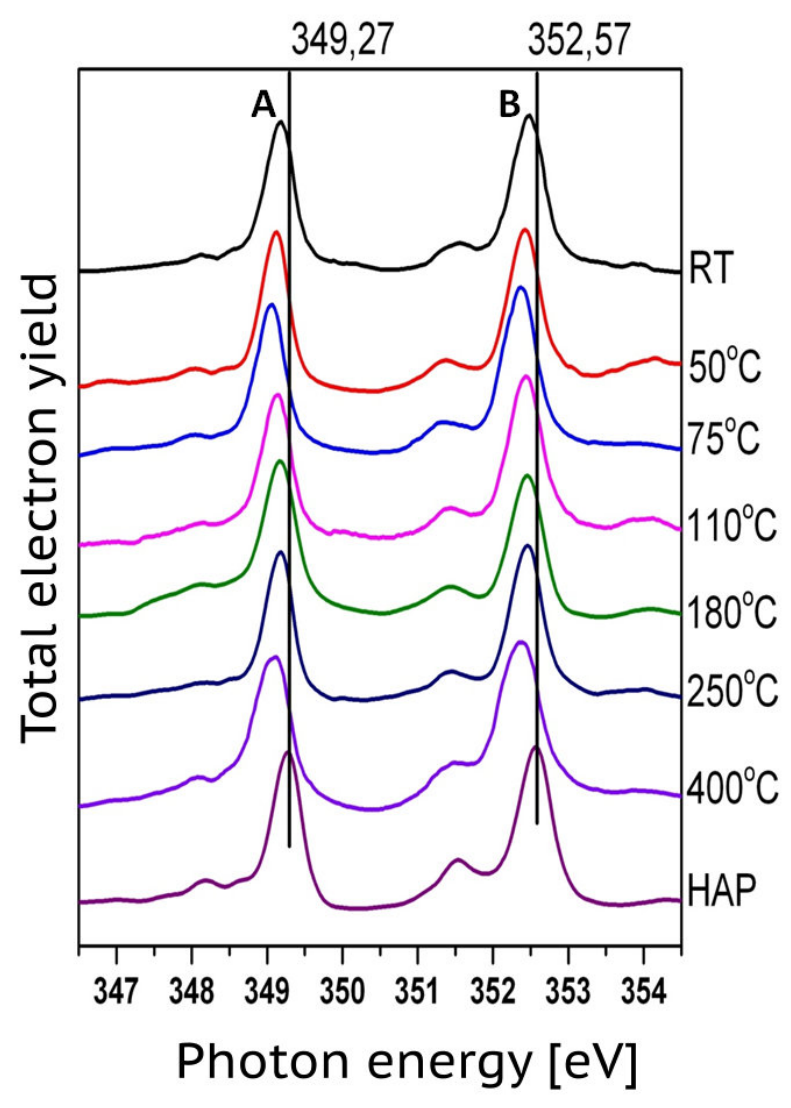

Figure 2. Spectral behavior of the TEY near the Ca $2 p$ edges in young bone heated 30 minutes at the temperature marked from the right side. The lowest curve is the reference spectrum of OH-Ap. The energy positions of the white lines $\mathrm{A}$ and $\mathrm{B}$ in $\mathrm{OH}-\mathrm{Ap}$ are shown by the vertical lines to visualize the $\mathrm{OH}-\mathrm{Ap}$-to-bone red shifts.

Table 1. The OH-Ap-to-bone red shifts and changes in FWHM of the Ca $2 p$ excitations A and B of mature bone as a function of heating temperature $\mathrm{T}$.

\begin{tabular}{ccccc}
\hline $\mathrm{T}\left({ }^{\circ} \mathrm{C}\right)$ & $\delta E_{A}^{m}(\mathrm{eV})$ & $\delta E_{B}^{m}(\mathrm{eV})$ & $\delta W_{A}^{m}(\mathrm{eV})$ & $\delta W_{B}^{m}(\mathrm{eV})$ \\
\hline $\mathrm{RT}$ & 0.2 & 0.2 & +0.2 & +0.2 \\
50 & 0.2 & 0.2 & 0 & 0 \\
60 & 0.2 & 0.2 & -0.1 & -0.1 \\
90 & 0.1 & 0.1 & +0.1 & +0.2 \\
103 & 0.2 & 0.3 & 0 & +0.1 \\
173 & 0.2 & 0.2 & +0.3 & +0.2 \\
180 & 0.1 & 0.2 & 0 & 0 \\
216 & 0.1 & 0.1 & +0.1 & +0.1 \\
280 & 0.3 & 0.3 & +0.2 & +0.2 \\
360 & 0.3 & 0.3 & +0.4 & +0.2 \\
450 & 0.1 & 0.1 & +0.2 & +0.4 \\
OH-AP & 0 & 0 & 0 & 0 \\
\hline
\end{tabular}


Table 2. The OH-Ap-to-bone red shifts and changes in FWHM of the Ca $2 p$ excitations A and B of young bone as a function of heating temperature $\mathrm{T}$.

\begin{tabular}{ccccc}
\hline $\mathrm{T}\left({ }^{\circ} \mathrm{C}\right)$ & $\delta E_{A}^{y}(\mathrm{eV})$ & $\delta E_{B}^{y}(\mathrm{eV})$ & $\delta W_{A}^{y}(\mathrm{eV})$ & $\delta W_{B}^{y}(\mathrm{eV})$ \\
\hline $\mathrm{T}$ & 0.1 & 0.1 & +0.1 & +0.2 \\
50 & 0.2 & 0.2 & 0 & 0 \\
75 & 0.2 & 0.2 & +0.1 & +0.2 \\
110 & 0.1 & 0.1 & +0.1 & +0.1 \\
180 & 0.1 & 0.1 & +0.2 & 0 \\
250 & 0.1 & 0.1 & +0.1 & +0.1 \\
400 & 0.2 & 0.2 & +0.2 & +0.2 \\
OH-AP & 0 & 0 & 0 & 0 \\
\hline
\end{tabular}

As for the $\mathrm{Ca} 2 \mathrm{p}$ excitations of young bone the maximal shifts $\delta E_{A}^{y} \approx \delta E_{B}^{y} \approx 0.2 \mathrm{eV}$ are reached twice at $50^{\circ} \mathrm{C}-75^{\circ} \mathrm{C}$ and $400^{\circ} \mathrm{C}$. Their maximal narrowing and broadening is observed at $50^{\circ} \mathrm{C}$ and $400^{\circ} \mathrm{C}$ respectively.

Since the $\mathrm{Ca}^{2+} 2 \mathrm{p}$ hole relaxation in native bone and OH-Ap is nearly the same the $\mathrm{Ca} 2 \mathrm{p}$ NEXAFS spectra evidence that the density of $\mathrm{Ca}^{2+} 3 \mathrm{~d}$ states in bone is distinctively shifted downward relative to the $3 \mathrm{~d}-$ band in $\mathrm{OH}-\mathrm{Ap}$ and demonstrates the specific thermal and age changes. These changes cannot be evidently rationalized in terms of the thermal phonon distribution in OH-Ap (see, e g. [36]). On this background we infer that the observed thermal-induced and age-related OH-Ap-to-bone variations of the Ca $2 p$ excitations are motivated by the composite nature of bone and tightly related with its hierarchical organization. By analyzing the changes we bring forward a suggestion that they are primarily controlled by dehydration and thermal-induced chemical reactions occurring in the hydrated-layers and nanocrystallite interfaces.

The thermal shifts $\delta E_{A}^{m(y)}(\mathrm{T})$ and $\delta E_{B}^{m(y)}(\mathrm{T})$ as well as the changes $\delta W_{A}^{m(y)}(\mathrm{T})$ and $\delta W_{B}^{m(y)}(\mathrm{T})$ are similar in magnitude. But they are not identical functions. In the low temperature regime (from RT up to $\approx$ $50^{\circ}-60^{\circ} \mathrm{C}$ ) one may see the narrowing of the A and B lines when T grows. In some cases the FWHM is narrower than that of in OH-Ap. This extra narrowing can be understood within the 3DSL model by combining the supertlattice and dehydration effects on electronic and atomic structure of bone [18]. For higher temperatures $\left(\mathrm{T}>250^{\circ} \mathrm{C}\right)$ the "white" lines become broader. We assign this broadening to the atomic restructuring as the number of non-equivalent calcium positions increases.

\section{Discussion}

Transmission electron microscopy and small angle X-ray scattering on bone makes it evident that intra- and inter-fibrilar associations of OH-Ap-nanocrystallites form a series of parallel and spiral wound mineralized 
plates $[5,10,18,37]$. These plates are usually described as coplanar assemblies of NOH-Ap submerged into the saturated aqueous solution containing $\mathrm{Ca}^{2+}, \mathrm{Mg}^{2+}, \mathrm{OH}^{-},\left[\mathrm{PO}_{4}\right]^{3-},\left[\mathrm{CO}_{3}\right]^{2-}$, and other ions $[7,10,18,37]$. Both the size distribution of nanocrystallites and their elemental composition in the plates differ in normal and pathological conditions $[10,11,17,22,38,39]$. The interplay of the $3 \mathrm{D}$ atomic structure of OH-Ap with the higher lying levels of the hierarchical organization of bone determines its nanolevel morphology.

The electronic and atomic structure of an individual mineralized plate is described as a 3D-superlattice assembled from the uniformly sized crystallites surrounded by the hydrated nanolayer [18]. The size of the effective NOH-Ap and the number of atoms per the crystallite can be approximated as $20 \times 7.5 \times 3.5 \mathrm{~nm}^{3}$ and 40000 respectively [17]. The advantage of the 3DSL model is the ability to link the band structure of the single-crystal OH-Ap (see, e.g. [41, 42]) with the electronic structure of native bone taking its hierarchical organization into account. This approach promotes a deeper understanding of the electronic and atomic properties of bone matter.

Considering the electronic and atomic structure of the single-crystal OH-Ap the main regularities inherent to the physical and chemical properties of the hierarchical nanostructure can be predicted and extracted. In particular, the electronic structure of the mineralized bone and its thermal properties can be described and computed by solving the Heine equation [18, 43]. Its solutions are determined by thermal dependence of the coefficient $\operatorname{Re}\left(1 / T T^{\prime}\right)$ where $T$ and $T^{\prime}$ are the amplitudes of electron transmission through the NOH-Ap and the hydrated nanolayer respectively. The amplitude $T^{\prime}$ attracts our special attention as it is regarded to be tightly related with the thermal-induced dehydration and the subsequent restructuring of the NOH-Ap interface. Thus, by examining the T-dependence of $T^{\prime}$ we have a chance to disentangle the thermal properties of mineralized phase and rationalize the observed $\mathrm{OH}$-Ap-to-bone changes $\delta E_{A(B)}^{m(y)}$ and $\delta W_{A(B)}^{m(y)}$ as functions of thermal load.

The Ca and P 2p and O 1s NEXAFS analysis performed in the work [18] has shown that at RT the ions $\mathrm{Mg}^{2+}, \mathrm{Ca}^{2+},(\mathrm{OH})^{-}$and $(\mathrm{PO})_{4}{ }^{3-}$ surrounded by the solvation shells $\left(\mathrm{H}_{2} \mathrm{O}\right)_{\mathrm{n}}$ play an important role in forming the electronic properties of mineralized bone. These shells shield effectively the columbic potential of the ions and weaken their chemical bonding with other atoms in the inter-crystallite space. The thermal treatment as it is stated in [25 - 27, 44] leads to the denaturation of mineralized collagen and to the removal of inter-crystallite water and, hence, to the unfolding of the solvation shells. This makes the columbic shielding less effective and induces restructuring of the NOH-Ap interface. Thus, both the dehydration of the nanolayers and the restructuring of the NOH-Ap interface in the coplanar assemblies are tightly related phenomena.

The experimental OH-Ap-to-mature-bone and $\mathrm{OH}-\mathrm{Ap}$-to-young-bone red shifts of the $\mathrm{Ca} 2 \mathrm{p}$ excitations display complex T-dependences. They cannot be evidently described in terms of the phonon broadening as the X-ray diffraction studies [45] display that the related cell volume of OH-Ap and the lattice parameters do not change noticeably up to $900^{\circ} \mathrm{C}$. By analyzing the experimental thermal-induced changes in bone we suggest two main mechanisms of their origin. The first mechanism is related with the dehydration of the inter-crystallite regions and leads to their approaching to empty spaces. Applying the 3DSL model to $\mathrm{NOH}-\mathrm{Ap}$ separated by empty spaces we expect both the gradual increase of the OH-Ap-to-bone red shift and 
the narrowing of the $\mathrm{Ca} 2 \mathrm{p}$ excitations in bone. The second mechanism is related with the atomic restructuring and changing of chemical bonds in the inter-crystallite space. Both the unfolding of the solvation shells for $\mathrm{T}>50-60^{\circ} \mathrm{C}$ and the degradation of the collagen matrix for $\mathrm{T}>340^{\circ} \mathrm{C}$ initiate new chemical reactions that form non-regular $\mathrm{Ca}^{2+}$ bonding sites in mineralized bone. The joint action of the mechanisms causes the irregular thermal behavior of the spectroscopic characteristics presented in tables 1 and 2 .

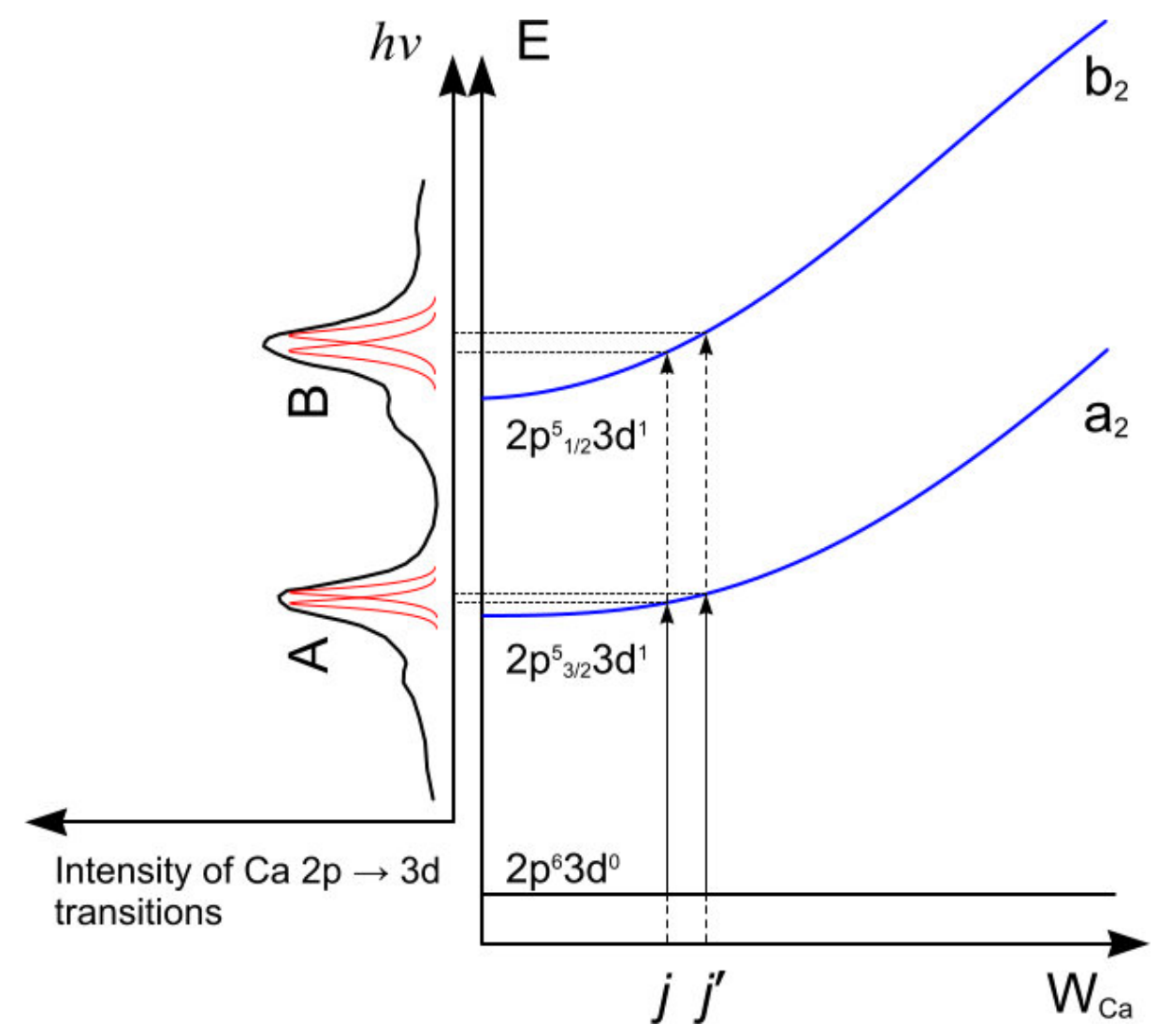

Figure 3. Schematic presentation of the surroundings effect on the A and B line shape in mineralized bone.

Figure 3 illustrates how the restructuring affects the $\mathrm{Ca}^{2+} 2 \mathrm{p}^{6} \rightarrow 2 \mathrm{p}^{5} 3 \mathrm{~d}^{1}\left(a_{2}\right)$ and $2 \mathrm{p}^{5} 3 \mathrm{~d}^{1}\left(b_{2}\right)$ line shapes in bone. Each position $(j)$ of $\mathrm{Ca}^{2+}$ is characterized by the surroundings potential $W_{\mathrm{Ca}(j)}$. The line shape $F_{A(B)}(\omega)$ of the transitions is obviously a sum over all non-equivalent bonding sites

$$
F_{A(B)}(\omega)=\sum_{j \in J(\mathrm{~T})} c_{j} f_{j}\left(\omega, \omega_{j}\right)
$$

Here $c_{j}$ and $J$ are the concentration of $\mathrm{Ca}^{2+}(j)$ ions and the number of the non-equivalent bonding sites, $h v_{j}$ is the transition energy dependent on the surrounding potential $W_{\mathrm{Ca}(j)}$. In bone the maximal number $J_{\max }$ of the non-equivalent positions is evidently bigger than in $\mathrm{OH}-\mathrm{Ap}$. In addition to the well-known $\mathrm{Ca} 1$ and $\mathrm{Ca} 2$ positions in $\mathrm{OH}-\mathrm{Ap}$ (see, e.g. $[41,46])$ there are $\mathrm{Ca}^{2+}$ ions surrounded by the solvation shells in the hydrated 
layers. On this background the set $J$ depends on $\mathrm{T}$ in (2). The distribution function $f_{j}\left(\omega, \omega_{j}\right)$ of an individual core-to-valence transition can be described with the Voight profile. The corresponding Lorentzian width specifies the inverse $\mathrm{Ca} 2 \mathrm{p}$-hole lifetime and Gaussian one is responsible for the bandwidth of the photon source and the phonon broadening in NOH-Ap. For simplicity only two $\mathrm{Ca}^{2+}(j)$ and $\mathrm{Ca}^{2+}(j$ ') positions are included in figure 3 . The figure illustrates the non-equivalent contributions of the $\mathrm{Ca}^{2+}(j$ ') $2 \mathrm{p}$ excitations to the absorption lines A and B. Since the energies of the terms $a_{2}$ and $b_{2}$ vary non-uniformly with changing the surrounding potential $W_{\mathrm{Ca}}$ these lines demonstrate different spectral shift and broadening. Thus, new $\mathrm{Ca}^{2+}$ bonding sites produce not identical changes in the line shape of the $\mathrm{Ca} 2 \mathrm{p}$ excitations. The spectroscopic data presented in tables 1 and 2 confirm the different behavior of the lines A and $\mathrm{B}$. This mechanism is expected to be dependent on the elemental composition of bone too but this aspect is not discussed here.

The experimental results show that the OH-Ap-to-bone red shifts and changes in the FWHM of the $\mathrm{Ca}$ $2 p$ excitations in the mature bone are more pronounced than in the young bone. To understand this difference, we draw our attention that amorphous calcium phosphate is also present in the mineralized bone [47]. The interrelationship of amorphous to crystalline phases changes rapidly with age. Using X-ray diffraction Termine and Posner [47] have demonstrated that the part of the amorphous material in the mineral composition of rat femur decreases with age. In particular, in a three-day-old bone the percentage of crystalline apatite and amorphous calcium is $32.8 \%$ and $67.2 \%$. In a 10 - and 80 -day-old bone these values are $37.6 \%$ and $62.5 \%$ as well as $63.1 \%$ and $32.9 \%$ respectively. So, in less than 80 days, the ratio changes in 4 times. The changing of the amorphous/crystalline mineral composition with increasing age is almost identical to the results obtained by using infrared spectroscopy and electron spin resonance method $[48,49]$. The noticeable presence of the amorphous component will weaken the influence of the super periodicity on the Ca $2 p$ excitations of young bone tissue. The experimental data in tables 1 and 2 support this effect. Note the temperature treatment also influences the interrelationship but much weaker. According to the work [47] the air drying of the mature bone samples at different temperatures resulted in changes of the amorphous component. Its contribution is $23.8 \%$ (at $\left.25^{\circ} \mathrm{C}\right), 29.9 \%\left(110^{\circ} \mathrm{C}\right)$ and $28.6 \%\left(250^{\circ} \mathrm{C}\right)$.

In the framework of the "black-nanoboxes-in-muddy-waters" concept [18] the 3DSL model describes the electronic structure of mineralized bone in terms of the electro-optical characteristics of its nanoelements. The thermal-induced dehydration and restructuring can be taken into account by introducing the T-dependent electro-optical thickness $\tilde{d}$ of the inter-crystallite region. Using the theoretical results [18] and the experimental data analysis we write the hierarchy induced OH-Ap-to-bone red shift of the $\mathrm{Ca}^{2+} 2 \mathrm{p} \rightarrow 3 \mathrm{~d}$ transitions in mineralized bone as

$$
\delta E_{3 \mathrm{~d}}(\mathrm{~T}) \approx 2 \gamma(\mathrm{T}) E_{3 \mathrm{~d}} \frac{\tilde{d}(\mathrm{~T})}{\langle L\rangle} .
$$

$\langle L\rangle$ is the mean size of the NOH-Ap in bone and $\gamma$ is the fraction of $\mathrm{Ca}^{2+}$ ions forming the superlattice to their total number in bone. Equation (3) describes the superlattice effect on the $2 p \rightarrow 3 d$ transition energy. It depends linearly on the $3 \mathrm{~d}$-band energy in $\mathrm{OH}-\mathrm{Ap} E_{3 \mathrm{~d}}$, the coefficient $\gamma$ and the ratio of the electron-optical 
thickness $\tilde{d}$ of the spacer layers to the mean linear size of the crystallite. According to [24] the OH-Ap-tobone spectral shift is not inherent in transitions occurring in $\mathrm{Ca}^{2+}$ ions which do not form the superlattice in bone. On this background we assume that the non-regular $\mathrm{Ca}^{2+}$ sites in the NOH-Ap interface and the amorphous material do not contribute to $\delta E_{3 \mathrm{~d}}(\mathrm{~T})$.

As an example, we use the values $E_{3 \mathrm{~d}} \approx 2 \mathrm{eV}[51], \gamma \approx 0.8$ [47], $\tilde{d} \leq 2 \mathrm{~nm}$ and $\langle L\rangle=\frac{1}{3}(20+7.5+$ $3.5) \approx 10 \mathrm{~nm}$ [18], apply (3) and obtain the OH-Ap-to-bone red shift in mature bone $\delta E_{3 \mathrm{~d}} \leq 0.3 \mathrm{eV}$. Thus, the 3DSL model estimation of the shift is in good agreement with the experimental data in table 1 . We also note that the thermal-induced changes of the shift $\delta E_{3 \mathrm{~d}}$ are determined by the coefficient and the geometric ratio $\tilde{d} /\langle L\rangle$ but its age-related changes are controlled by the $\gamma$ and the mean size $\langle L\rangle$.

The important role of the dehydration and restructuring mechanisms in the thermal-induced changes is supported by the near O 1s edge NEXAFS [18] and infra-red (IR) spectroscopic studies [50 - 52]. The suppression of the lowest $\mathrm{O} 1 \mathrm{~s}$ absorption peak located at $532.2 \mathrm{eV}$ and the $3400 \mathrm{~cm}^{-1}$ band in IR spectra of heated bone points unambiguously on the thermal-induced removal of water from the intercrystallite space $[18,51]$ and the destruction of the $\mathrm{OH}^{-}\left(\mathrm{H}_{2} \mathrm{O}\right)_{\mathrm{m}}$ and $\mathrm{Mg} / \mathrm{Ca}^{2+}\left(\mathrm{H}_{2} \mathrm{O}\right)_{\mathrm{n}}$ clusters [18] that dominate the solvation structure in bone at RT. It is the electronic transitions from $\mathrm{O} 1 \mathrm{~s}$ level to the low unoccupied molecular orbitals in the clusters that are regarded as the main origin of the $532.2 \mathrm{eV}$ absorption peak [18]. The broad band in IR spectra is tightly related with $\mathrm{O}-\mathrm{H}$ vibrations give rise in hydrated layers in bone. The molecular dynamic simulations [53] performed to understand the hydration thermodynamics of $\mathrm{Ca}^{2+}$ and other ions indicate that the van-der-Waals interaction forms the solvation shells with the average coordination number 7.3. This number agrees with the experimental values extracted from the X-ray, neutron scattering and EXAFS measurements [53 - 56]. Thus, the suppression of both the absorption peak at $532.2 \mathrm{eV}$ and the vibration band at $3400 \mathrm{~cm}^{-1}$ in heated bone $[18,51,52]$ makes evident importance of the dehydration and restructuring mechanisms in the hydrated-layer-NOH-Ap-surface network in bone tissue.

Further experimental and theoretical research of local electronic and atomic structure of bone is required. The probing by using $\mathrm{O} 1 \mathrm{~s}$ and $\mathrm{P} 2 \mathrm{p}$ excitations and performing in-situ X-ray absorption measurement of bone samples and their thermal treatment will permit us to increase the accuracy and to understand in more detail the link of electron and atomic structure with the hierarchical organization of skeleton.

\section{Conclusion}

The performed high energy resolution Ca $2 p$ NEXAFS measurements of mature and young bones have (i) confirmed the predicted OH-Ap-to-bone red shift of the calcium 3d-states, (ii) revealed the irregular temperature dependence of the $\mathrm{Ca} 2 \mathrm{p}$ excitations of bone tissue and (iii) demonstrated the different thermal dependence of the line shapes and the $\mathrm{Ca} 2 \mathrm{p} \rightarrow 3 \mathrm{~d}$ transition energies in mature and young bone. The measured OH-Ap-to-bone red shifts of the transition energy vary irregular in the interval $0.1 \mathrm{eV} \leq \delta E_{3 \mathrm{~d}} \leq 0.3 \mathrm{eV}$ when $\mathrm{T}$ grows from RT up to $450^{\circ} \mathrm{C}$. At RT the shifts are found equal $\delta E_{A}^{m} \approx \delta E_{B}^{m} \approx 0.2 \mathrm{eV}$ and $\delta E_{A}^{y} \approx$ 
$\delta E_{B}^{y} \approx 0.1 \mathrm{eV}$ for mature and young bone respectively. The shifts averaged over the heating $\mathrm{T}$ interval are $0.18 \mathrm{eV}, 0.2 \mathrm{eV}$ and $0.14 \mathrm{eV}$.

The thermal-induced dehydration of the nanolayers leads to the unfolding of solvation shells of ions in the hydrated layers, which launches new chemical reactions as the dielectric shielding weakens and to the subsequent restructuring of the interface in bone.

The 3DSL model gives us a key for understanding the relationship between the hierarchical organization of bone tissue and its electronic and atomic structure, thermodynamics and spectral distribution of oscillator strength for core-to-valence transitions in it.

\section{Acknowledgment}

This work was performed in part within the bilateral Program "Russian-German Laboratory at BESSY" (Helmholtz Zentrum Berlin (HBZ), proposal No.17105064-ST). The authors gratefully acknowledge the financial support by HZB and also thank HZB for the allocation of synchrotron radiation beamtime. This work was also supported by the Russian Foundation for Basic Research (Grant No.15-02-06369). The authors would like to honor the memory of Dr. Alexander Avrunin who actively participated in the studies.

\section{References}

[1] Weiner S and Wagner H D 1998 Annu. Rev. Mater. Sci. 28 271-98

[2] Currey J 2001 Nature 414699

[3] Buehler M 2007 Nanotechnology 18295102

[4] Avrunin A S, Tikhilov R M, Abolin A B and Shcherback I G 2005 Morfologiia 2 78-82 (in Russian)

[5] Avrunin A S, Tikhilov R M, Shubniakov I I, Parshin L A, Melnikov B E and Pliev D G 2010 Morfologiia 6 69-75 (in Russian)

[6] Fratzl P and Weinkamer R 2007 Prog. Mat. Sci. 52 1263-334

[7] Neuman W F and Neuman M W 1958 The Chemical Dynamics of Bone Mineral (Chicago: University of Chicago Press)

[8] Hancox M N 1972 Biology of Bone (Cambridge: Cambridge University Press)

[9] Currey J 1984 The Mechanical Adaptation of Bones (Princeton, NJ: Princeton University Press)

[10] Avrunin A S, Denisov-Nikolsky Y I, Doktorov A A, Krivosenko Y S, Samoilenko D O, Pavlychev A A and Shubniakov I I 2015 Traumatologiya Ortopediya Rossii 3 37-50 (in Russian)

[11] Wopenka B and Pasteris J D 2005 A mineralogical perspective on the apatite in bone Mater. Sci. Eng. C 25 131-43

[12] Long S and Romani A M P 2014 Role of cellular magnesium in human diseases Austin J Nutr Food Sci. 2 1-19 
[13] Reiche I, Lebon M, Chadefaux C, Muller K, Anne-Solenn H, Gensch M and Schade U 2010 Anal. Bioanal. Chem. 397 2491-99

[14] Chadefaux C, Vignaud C, Chalmin E, Robles-Camacho J, Arroyo-Cabrales J, Johnson E and Reiche I. 2009 Am. Mineral. 94 27-33

[15] Knothe Tate M L 2007 Engineering of functional skeletal tissues (Topics in Bone Biology vol 3) ed F Bronner; M C Farach-Carson and A G Mikos (London: Springer) pp 141-60

[16] Bertazzo S, Bertran C A 2006 Key Eng. Mater. 309-311 3-6

[17] Yucesoy B., Charles L E., Baker B and Burchfiel C M 2015 Occupational and genetic risk factors for osteoarthritis: A review Work 50 261-73.

[18] Pavlychev A A, Avrunin A S, Vinogradov A S, Filatova E O, Doctorov A A, Krivosenko Y S, Samoilenko D O, Svirskiy G I, Konashuk A S and Rostov D A 2016 Nanotechnology 27504002

[19] Gautieri A, Vicentini S, Redaelli A and Buehler M 2011 Nano Lett. 11 757-66

[20] Dorozhkin S V 2015 J. Funct. Biomater. 6 708-832

[21] Currey J D 1964 Biorheologi 2 1-10

[22] Zhilkin B A, Denisov-Nikolski Y I and Doktorov A A 2003 Usp. Sovremennoy Biologii 123 590-8 (in Russian)

[23] Nikolaev A, Bazhenov V V, Frank-Kamenetskaya O V and Petrova O V 2017 Psychrofilic calcification in-vitro Extreme Biomimetics ed. H Ehrlich (Springer International Publishing) p 81-96 (DOI: 10.1007/978-3-319-45340-8)

[24] Samoilenko D O, Avrunin A S and Pavlychev A A 2017 Eur. Phys. J. D 71 180-4

[25] Wopenka B and Pasteris J D 2005 A mineralogical perspective on the apatite in bone Mater. Sci. Eng. C 25 131-43

[26] Yoder C H, Pasteris J D, Worcester K N and Schermerhorn D V 2012 Calcif. Tissue Int. 90 60-7

[27] Bozec L and Odlyha M 2011 Thermal denaturation studies of collagen by microthermal analysis and atomic force microscopy Biophys. J. 101 228-236

[28] Xu Z and Buehler M 2009 Hierarchical nanostructures are crucial to mitigate ultrasmall termal point loads Nano Lett. 9 2065-72

[29] Lukirskii A P and Brytov I A 1964 Sov. Phys - Solid State 6 43-53

[30] Gudat W and Kunz C 1972 Phys. Rev. Lett. 29 169-72

[31] de Groot F M F, Fuggle J C, Thole B T and Sawatsky G A 1990 Phys. Rev. B 41 928-37

[32] Metzler R A and Rez P 2014 Polarization dependence of argonite calcium L-edge XANES spectrum indicates $\mathrm{c}$ and $\mathrm{b}$ axes orientation J. Phys. Chem. B 118 6758-66

[33] Rajendran J, Gialanella S and Aswath P B 2013 Sci. Eng. C 33 3968-79

[34] Naftel S J, Sham T K, Yiu Y M and Yates B W 2001 J. Synchrotron Radiat. 8 255-7

[35] Cosmidis J, Benzerara K, Nassif N, Tyliszczak T and Bourdelle F 2015 Acta Biomater. 12 260-9

[36] Ziman J M Principles of the Theory of Solids 2nd edition (Cambridge: Cambridge University Press) p 435 (https://doi.org/10.1017/CBO9781139644075) 
[37] Denisov-Nikolski Y I, Mironov S P and Omeljanenko N P 2005 Actual Problems of Theoretical and Clinical Osteoartrology (Moscow: Novosti)

[38] Legros R, Balmain N and Bonel G 1987 Calcif. Tissue Int. 41 137-44

[39] Tong W, Glimcher M J, Katz J L, Kuhn L and Eppell S J 2003 Calcif. Tissue Int. 72 592-8

[40] Taylor A J, Rendina E, Smith B J and Zhou D H 2013 Chem. Phys. Lett. 588 124-30

[41] Rulis P, Ouyang L and Ching W Y 2004 Phys. Rev. B 70155104

[42] Matsunaga K and Kuwabara A 2007 Phys. Rev. B 75014102

[43] Heine V 1970 Solid State Phys.: Adv. Res. Appl. 24 1-36

[44] Bonar L C and Glimcher M J 1970 J. Ultrastruct. Res. 32 545-8

[45] Zanotto A, Saladino M L, Martino D C, Caponetti E 2012 Influence of temperature on calcium hydroxyapatite Advances In Nanoparticles $121-8$

[46] Renaudin G, Gomes S and Nedelec J-M 2017 First-row transition metal doping in calcium bioceramics: A detailed crystallographic study Materials 1092

[47] Termine J D and Posner A S 1967 Calcif. Tissue Res. 1 8-23

[48] Termine J D and Posner A S 1966 Science 153 1523-5

[49] Termine J D 1966 Amorphous Calcium Phosphate: The Second Mineral of Bone Ph.D. Thesis (Cornell University, Ithaca, $N Y$, US)

[50] Nyman J S, Makowski A J, Patil C A, Masui T P, O’Quinn E C, Bi X, Guelcher S A, Nicolela D P and Mahadevan-Jansen A 2011 Calcif. Tissue Int. 89 111-22

[51] Rajendran J 2011 XANES and FTIR Study of Dried and Calcined Bones Master Thesis (The University of Texas at Arlington, Arlington, Texas, US)

[52] Mkukuma L D, Skakle J M S., Gibson I R, Imrie C T, Aspden R M and Hukins D W L 2004 Calcif. Tissue Int. 75 321-8

[53] Jiao D, King C, Grossfield A, Darden T A and Ren T 2006 Simulation of $\mathrm{Ca}^{2+}$ and $\mathrm{Mg}^{2+}$ solvation using polarizable atomic multipole potential J. Phys. Chem. B $11018553-9$

[54] Caminiti R, Licheri G, Piccaluga G and Pinna G 1977 Chem. Phys. Lett. 47275

[55] Hewish N A, Neilson G W and Enderby J E 1982 Nature 297138

[56] Megyes T, Grosz T, Radnai T, Bako I and Palinkas G 2004 J. Phys. Chem. A 1087261

[29] Nikolaev A, Kuz'mina M, Frank-Kamenetskaya O and Zorina M 2015 J. Mol. Struct. 1089 73-80 